\title{
Reflections on Developing the Student Consultants for the Teaching and Learning Program at Reed College, USA
}

\author{
Kathryn C. Oleson, Department of Psychology, Reed College, Portland, Oregon, USA \\ Contact: koleson@reed.edu \\ Knar Hovakimyan, Department of Linguistics, Reed College, Portland, Oregon, USA
}

\section{DEVELOPING OUR PROGRAM}

At Reed College, many classes are taught as discussion-based conferences in which students and faculty must come prepared to engage in dialogue about the day's material, take risks and feel discomfort as they challenge themselves, and create shared ownership in their own active learning (Oleson, 2015). Collaboration is fundamental. The Center for Teaching and Learning (CTL) opened in Fall 2014 to help faculty develop and improve their methods of instruction and to promote productive pedagogical feedback to professors (Oleson, 2016). In 2014, we started a student-consultant program at Reed since faculty-student partnerships seemed a promising approach for faculty to receive feedback essential for improvement (CookSather, Bovill, \& Felten, 2014). This essay, reflecting on the development of the program, was co-written by Kathy Oleson, Professor of Psychology and former Director, Center for Teaching and Learning at Reed College (2014 - 2016) and Knar Hovakimyan, Reed College '16, studentconsultant for four semesters. Shifts in perspective from one author to the other are indicated with the particular author's first name included in brackets following the pronoun.

Bryn Mawr and Haverford's Students as Teachers and Learners (SaLT) program coordinated by Alison Cook-Sather was on Reed College's radar as we set the foundation for our CTL. As part of a Mellon Foundation-funded pilot grant, Reed professors visited CTLs across the country, including Bryn Mawr and Haverford's Teaching and Learning Institute, to learn about best practices. During the 2013-2014 school year, a team of three professors, one staff member, and four students who were piloting a student-consultant program at Reed invited Alison Cook-Sather to visit in late February. Seeking input from an expert was critically important in developing our own student-consultant program at Reed.

Alison met with me (Kathy), the incoming director of Reed's new CTL, during her visit. She also conducted a workshop for 26 faculty and staff on "Partnering with Students to Promote Active and Engaged Learning." Given the enthusiasm generated by her visit, the eightperson team conducting the pilot program hosted a follow-up luncheon panel during finals week that 30 staff and faculty attended. This panel provided faculty with details about Reed's 
pilot program and served as a link between the ideas in Alison's broader workshop to Reed's particular context. Knowing that many professors were interested in participating in a similar program and with strong support from the Dean of Faculty, I established the Student Consultants for Teaching and Learning Program as a defining part of the Center's programming. I formally launched it in Fall 2014 and it continues today. Our Student Consultants for Teaching and Learning Program pairs faculty members with students who act as paid consultants to instructors by providing them with targeted feedback on their teaching.

I initially emailed faculty who took part in Alison's workshop or who attended the panel to see if they would like to participate, starting with those who had shown interest. Any professor who asked to be a part of it was in. The first semester we had six faculty-student partnerships but that number grew to seventeen by the second semester. Seventeen pairs was the upper limit of what I could facilitate. I wanted the program to be inclusive; now we solicit participation from all faculty. Initially, some professors expressed concerns about having a student "evaluating" them in class. From the beginning, I stressed that they would be partnering with students and that I would not be writing evaluations as the director. To build trust and openness, I emphasized that the program was for development and improvement and separate from the evaluation process. Over time, these concerns dissipated based on the enthusiasm generated by the pilot program and, later, by word of mouth.

From the beginning, our program has involved flexibility, with faculty at varying levels of seniority volunteering to participate and each partnership determining the specific details of their work together. The structure of the program includes many features of Bryn Mawr and Haverford's SaLT program. Alison's generosity in sharing her SaLT materials for us to use as templates ensured a high quality foundation. The student consultants (who are not enrolled in the faculty member's class) and professors are paired before the semester begins. For students, it is a paid job - one of the best ones on campus, according to my consultants. Students submit a cover letter and resume and ask a professor to recommend them. Talking to professors providing references gives me (Kathy) an opportunity to explain the program to faculty. Professors volunteer and do not receive compensation or course releases; unlike those participating in the SaLT program, they do not attend any course meetings. They attend a few lunches. Professors are free to request a specific student as their consultant; alternatively, they indicate preferred consultant qualities (e.g., that the student has taken the relevant class, that the professor does not know the student) and the director pairs them. One challenge is creating a large pool of consultants with various qualities. I have encouraged faculty to nominate students. It is also important to ensure that this position is well advertised.

The faculty-student collaboration is maintained throughout the semester as the student consultant attends class sessions, taking extensive notes about what happens in the classroom. The specifics are determined within each partnership. Sometimes the consultant observes once a week, whereas in other partnerships they observe every class meeting. Sometimes the partnership begins with the consultant attending one course and then switching to another one. Giving faculty-student pairs autonomy was important (Deci \& Ryan, 2000), although students and faculty were encouraged to contact me (Kathy) if issues came up. The pairs had confidential conversations each week to discuss the course. As a professor noted in anonymous feedback, "It was also a really nice way to spend one hour per week-discussing 
pedagogical theory, practice, and strategies. Something that I don't do very often with my colleagues."

Additionally, there are weekly meetings of all student-consultants with the director. Students discuss the goals that they are working on in their courses, provide support and advice to each other, and learn new techniques. Finally, the consultant solicits for the professor written and in-class verbal midterm feedback from students in the class. These key structural elements are important in the program's success (Pitts \& Baumgardner, 2016).

\section{SUCCESS OF REED'S PROGRAM}

This program has been highly successful at Reed, with six or more faculty participating each semester. A few key features help to explain why the program thrives. First, unlike some student-consultant programs at other colleges, faculty members at different stages in their careers have taken part. For instance, the first semester included four junior faculty and two senior faculty, all highly motivated to participate and improve. More faculty at all stages participated the next semester. Including senior professors widely viewed as effective teachers provided legitimacy. Additionally, it showed that the purpose of the program was not only to learn to be a better teacher but also to develop teaching styles to grow with the students and culture on campus.

Second, many faculty participants want to keep participating. All six professors who took part that first fall asked if they could continue the next spring. We decided it was best to have new faculty-student pairings, but I (Kathy) allowed all to participate again which, in retrospect, was a great decision. Ten additional professors and one staff member who teaches a not-forcredit student leadership class wanted to participate the next spring. We had the funds to pay for seventeen consultants. The best advertising that our program could have was faculty who found it valuable enough to keep committing time and energy to it over multiple semesters.

Third, each faculty-student partnership is shaped by the goals of the professor. During the first meeting, faculty explain to their consultant what they hope to accomplish in the program, where their problem areas are, and what the focus should be throughout the semester. The goals determine where the consultant concentrates their note-taking and discussions with faculty; without a clear articulation of what they are trying to accomplish or a commitment to meeting regularly to work on these goals, partnerships can falter. The flexibility in setting goals allows for professors to take advantage of the program for their particular teaching goals. As the program director, I (Kathy) met each week with the consultants to provide training in communicating constructively, taking effective notes, and so forth. I received feedback from some faculty that their consultants were being "too nice." This is understandable-students are being put in a new role of providing critical feedback to faculty in a one-on-one conversation. I made it clear that faculty volunteered for this program because they were open to feedback and wanted to make changes. This training was done in a group conference format and was adapted to support the particular teaching goals and issues that came up in the various classes.

I (Knar) worked as a consultant with four different professors at different stages in their careers and teaching completely different topics in completely different styles. In some classes I was familiar with the subject matter, but, in others, it was new to me. In each case, I felt that my job was to team up with the professor to help them address whichever issues they wanted 
to work on. For example, when I was working in a conference-style humanities course, my observations and comments were focused on class dynamics and how the students were responding to each other and the professor. When working in a biology lecture course, I focused my attention on the clarity of the presentation slides, and the professor's movement through the material. I would discuss these different strategies and situations in weekly meetings with Kathy, and she would provide training to support my particular partnership.

\section{THE UNIQUE VALUE OF STUDENT CONSULTANTS}

A consultant has a unique take on what goes on in a classroom. As a student who is among their peers, a consultant is able to understand what's happening in the classroom from the students' perspective. At the same time, by meeting weekly with the professor to discuss concerns, issues, and goals, the consultant also understands the classroom in terms of the professor's intentions. As a team, a student-consultant and professor can think critically about ways to improve the class that might be difficult to see without working in the program (see Wagner-McCoy \& Schwartz, 2016, for additional examples.)

During my (Knar) second semester as a consultant I was working with a professor who told me that their biggest concern was running out of time during lecture. For most of the semester, we worked on time-management strategies and presentation techniques that would ensure all the material would be covered. When I collected the mid-course feedback, many students commented that the professor was moving through the material too quickly during lectures. Both the students and professor were identifying the pace of the lecture as a problem, but when I met with the professor, we were able to dig deeper by thinking back to previous discussions and looking back at notes. We realized that the problem was that students did not have enough graded work outside of the classroom. Since students were not doing the foundational work that would prepare them for lecture, they were unable to understand as well as the professor expected them to. As a result, the professor would spend more time in class answering questions and would run out of time to cover the material. By looking at these types of problems together and dedicating time to talking about them, the professor and student consultant can see deeper issues and work on innovative and creative ways to deal with them.

\section{EFFECTS ON FACULTY}

The program has transformed professors' experiences in the classroom, their overall approaches to pedagogy, and the quality of their teaching. One faculty participant wrote in anonymous feedback about the program:

The benefits were many. In some ways, it was just fun to have a partner of sorts in the classroom with whom I could debrief. It made the experience less lonely, for lack of a better term. The comments were very helpful in producing greater awareness of the ways my actions impact discussion. I hope that I can maintain this sense of perspective in future semesters.

Another professor wrote: 
I felt true collaboration with my [student consultant]. They brought excitement that matched mine to the course and the problem solving of how to encourage great discussion in class. They also served as a support and cheerleader at times when I felt unsure or frustrated. The most productive elements were the weekly meetings and wonderful classroom notes.

As Luker and Morris (2016) stress in their recent essay reflecting on participating in Reed's student-consultant program, "collaboration is powerful."

Two of the faculty participants, Kara Becker and Michael Pitts, recently received tenure. In their tenure dossiers, they wrote eloquently about its impact on their teaching. As Michael Pitts noted:

The most significant factor that has helped improve my teaching has been my participation in Reed's 'student consultant program' run by the Center for Teaching and Learning. I've now participated in this excellent program during three separate semesters for three different courses... The most important skill I learned through participating in the teaching consultant program is how to better focus my attention on classroom dynamics and students' comprehension of the material.

\section{Kara Becker wrote:}

I have participated for four semesters in the Student Consultants program offered through Reed's Center for Teaching and Learning. This experience has been by far the most productive activity related to my growth as a teacher.... A key takeaway from my participation in this program was that all students should be treated in a way as "consultants." I've found that the more I include my students in a conversation about why we're doing what we're doing, the more they are empowered to take ownership over the process....I'm proud of the progress I've made as a teacher and am thankful to have developed relationships with students who were both peers and supports to me during the last two years.

\section{EFFECTS ON STUDENTS}

The program instills a feeling of value in students. Consultants learn that their ideas and feedback are immensely valuable to faculty (often much to the student's surprise). When asked to provide advice for future consultants, an anonymous consultant shared:

I think one of the most important things is to remember that your faculty partner is probably Really Excited about doing this. They think that you are valuable! They think that your notes, your time, and your insights are all worthwhile, whether or not you are an expert in whatever they are teaching.

The students in student-consultant classes also learn the importance of their role in class. One student-consultant anonymously shared: "As a student I take away an understanding 
of my own influence in the classroom, as well as ideas for how to collaborate more fully." These lessons are helpful to students' individual success as well as the success of the entire classroom.

For me (Knar), it was daunting to build a partnership with a professor, and at the beginning of each new partnership, I struggled to feel useful. It was challenging to step out of my student shoes and play an entirely different role in the classroom, where the professor would rely on my understanding of what was going on and my ideas about it. I was surprised by how helpful I was able to be to my faculty partners. I started to give feedback to other professors with whom I was not consulting. I would tell them which materials I found most helpful in class, but when problems came up, it was still difficult for me to approach them. I found myself wishing that each of my classes had a student consultant. Similarly, some students who applied to work as student-consultants noted on their applications that they were interested in the program because they had had a student-consultant in a previous class.

\section{EFFECTS ON CLASSROOM CULTURE}

This program encourages students and professors to actively work on making the classroom the best learning environment that it can be. Students working as consultants gain perspective on what teaching and preparing a class entails. This insight was so helpful to me (Knar) that I often suggested to faculty that they be clearer about their intentions in the classroom in order to help their students know how to succeed. There is a level of transparency that inherently goes along with the program, which in itself is beneficial to the class (see Becker \& Wood, 2016, for further consideration of the positive role of transparency). In my experience, students in a student-consultant class are more aware of their personal responsibility to the rest of the class.

The experimentation that happens in student-consultant classes contributes to this sense of openness in the classroom. Sometimes a strange new assignment or structure to the classroom produces great results (and sometimes not). Professors who have been teaching for decades can try something completely different with their consultant and get regular and immediate feedback. The experimentation shows students that faculty are actively working on improving the classroom. This pushes students to focus on their personal roles. The willingness in students and faculty to come up with and execute innovative and creative solutions through the student-consultant partnerships helps our program shine.

The pedagogical reflection that occurs in the program also has an impact on campus culture. As one consultant anonymously shared:

I've generally felt a much deeper connection to, and appreciation for, Reed. I really love that Reed supports this program, and encourages professors to be thoughtful in their teaching. It has made me feel more appreciative of my classes and the school generally.

A consultant emailed me (Kathy) thoughts they had shared with their faculty partner, noting:

The project of constantly reflecting on the process of teaching will continue to change the way students and professors interact with the pedagogical process. When a course is treated as a living, malleable entity, students will engage with it more. 
The transparency between faculty and students, the experimentation in studentconsultant classrooms, and the reflection on teaching establishes a sense of teamwork for everyone involved. Both students and professors have a sense of responsibility for learning and contributing to the class. This effect does not stop at classrooms with consultants. Much of what students and faculty learn in the program has an impact outside of the program, not just for themselves but for others on campus, whether through word-of-mouth or workshops conducted by the CTL. We too find ourselves impacted by our involvement with this program, agreeing with the ending sentiment of an email Kathy recently received: "To conclude, Kathy, I consider my job as a student consultant to be one of the best things I did at Reed."

\section{ACKNOWLEDGEMENTS}

Preparation of this article was supported by the Blair Wellensiek and Karl Peters Faculty Research Fund. We are grateful to Kara Becker and Michael Pitts for giving their permission to quote from their tenure dossiers. We would like to thank the many students and faculty who participated with us in the Student Consultants for Teaching and Learning Program at Reed.

\section{NOTES}

1. In some previous presentations of this program, it was referred to as the StudentConsultant or Student-Consultants for Teaching and Learning Program.

\section{NOTES ON CONTRIBUTORS}

Knar Hovakimyan is an alumna of Reed College, where she studied linguistics with a focus on phonetics. She worked as a student consultant at Reed from 2014-2016.

Kathryn Oleson is Professor of Psychology and former Director of the Center for Teaching and Learning at Reed College. Her research explores ways to make the college classroom more inclusive, particularly focusing on productive discomfort. Her teaching includes Introductory Psychology, Data Analysis, Social Psychology, Interpersonal Perception, and Stereotyping and Prejudice.

\section{REFERENCES}

Becker, K. \& Wood, A. (2016). Group dynamics: Lessons and surprises from multiple sections of a single class. Teaching and Learning Together in Higher Education, 1(17), 1-9. Retrieved from http://repository.brynmawr.edu/tlthe/vol1/iss17/4

Cook-Sather, A., Bovill, C., \& Felten, P. (2014). Engaging students as partners in teaching and learning: A guide for faculty. San Francisco: Jossey-Bass.

Luker, M. \& Morris, B. (2016). Five things I learned from working with the Student-Consultant 
for Teaching and Learning Program. Teaching and Learning Together in Higher Education, 1(17), 1-5. Retrieved from http://repository.brynmawr.edu/tlthe/vol1/iss $17 / 2$

Oleson, K. C. (2015). The art of the conference: Is there a secret formula for great class discussion? Reed Magazine, 94(3), 20.

Oleson, K, C. (2016). Introduction - Collaborating to develop and improve classroom teaching: Student-Consultant for Teaching and Learning Program at Reed College. Teaching and Learning Together in Higher Education, 1(17), 1-3. Retrieved from http://repository.brynmawr.edu/tlthe/vol1/iss17/1

Pitts, M. \& Baumgartner, H. (2016). Benefits of participating in the student consultant program across multiple semesters. Teaching and Learning Together in Higher Education, 1(17), 1-6. Retrieved from http://repository.brynmawr.edu/tlthe/vol1/iss17/5

Ryan, R. M., \& Deci, E. L. (2000). Self-determination theory and the facilitation of intrinsic motivation, social development, and well-being. American Psychologist, 55, 68-78. http://repository.brynmawr.edu/tlthe/vol1/iss17/5

Wagner-McCoy, S. \& Schwartz, E. (2016). Gaining new perspectives on discussion-based classes in English and the humanities. Teaching and Learning Together in Higher Education, 1(17), 1-9. Retrieved from http://repository.brynmawr.edu/tlthe/vol1/iss17/3 